\title{
Control of inducible chemoresistance: Enhanced anti-tumor therapy through increased apoptosis by inhibition of NF-kB
}

\author{
Cun-Yu Wang ${ }^{1,2,3}$, James C. Cusack, JR. ${ }^{1,4}$, Rong LiU ${ }^{1} \&$ Albert S. Baldwin, JR. ${ }^{1,3,5}$ \\ ${ }^{1}$ Lineberger Comprehensive Cancer Center, ${ }^{2}$ Department of Endodontics, School of Dentistry, ${ }^{3}$ Curriculum in \\ Genetics and M ol ecular Biology, ${ }^{4} \mathrm{D}$ epartment of Surgery, ${ }^{5} \mathrm{D}$ epartment of Biology, University of N orth Carolina at \\ Chapel Hill, Lineberger Comprehensive Cancer Center, Campus Box 7295, North Carolina 27599-7295, USA \\ C.-Y.W. \& J.C.C. contributed equally to the study \\ Correspondence should be addressed to A.S.B. or J.C.C.
}

\begin{abstract}
Programmed cell death (apoptosis) seems to be the principal mechanism whereby anti-oncogenic therapies such as chemotherapy and radiation effect their responses. Resistance to apoptosis, therefore, is probably a principal mechanism whereby tumors are able to overcome these cancer therapies. The transcription factor NF- $\mathrm{KB}$ is activated by chemotherapy and by irradiation in some cancer cell lines. Furthermore, inhibition of NF- $\mathrm{KB}$ in vitro leads to enhanced apoptosis in response to a variety of different stimuli. We show here that inhibition of NF-KB through the adenoviral delivery of a modified form of $\mathrm{I} \kappa \mathrm{B} \alpha$, the inhibitor of $\mathrm{NF}-\mathrm{K} \mathrm{B}$, sensitizes chemoresistant tumors to the apoptotic potential of TNF $\alpha$ and of the chemotherapeutic compound CPT-11, resulting in tumor regression. These results demonstrate that the activation of NF- $k B$ in response to chemotherapy is a principal mechanism of inducible tumor chemoresistance, and establish the inhibition of NF- $\mathrm{kB}$ as a new approach to adjuvant therapy in cancer treatment.
\end{abstract}

Resistance of tumors and hematological neoplasms to chemotherapies is a common clinical problem in human cancer ${ }^{1}$. Resistance to chemotherapies may already exist before the initiation of therapy because of overexpression of the multidrug resistance gene product MDR1, which functions to export a variety of chemotherapies from tumor cells. Moreover, chemoresistance (acquired or inducible) may develop in response to chemotherapy by mostly unknown mechanisms. Apoptosis (programmed cell death) seems to be the main mechanism whereby chemotherapy and radiation induce the killing of tumor cell $s^{1,3-5}$. Apoptosis also serves as a cell-killing mechanism induced by cytokines such as tumor necrosis factor $\alpha$ (TNF $\alpha$ ) (ref. 6). Apoptosis induced by TNF $\alpha$ and by chemotherapy and radiation seem to require, at least partially, the activation of the caspase cascade, leading to proteolytic cleavage of a variety of important proteins and ultimately to cleavage of cellular DNA (refs. $4,6,7)$. TNF $\alpha$, chemotherapy, radiation and other stimuli activate the transcription factor NF- $\mathrm{kB}$, and this response potently suppresses the apoptotic potential of these stimuli in vitro ${ }^{8-12}$. Here we analyzed the effect of inhibition of NF-kB in parallel with TNF $\alpha$ or chemotherapy treatment on experimental tumors. Our data establish that the inhibition of NF- $\mathrm{kB}$ activation in tumors through the adenoviral delivery of a modified form of $I \kappa B \alpha$, the natural inhibitor of NF-kB (refs. 13,14), functions to substantially enhance the apoptotic potential of cancer therapies. Thus, NF-kB activation serves as a principal mechanism for inducible resistance to chemotherapy, and inhibition of NF-kB could be a new adjuvant approach for cancer treatment.

\section{TNF $\alpha$ elicits tumor regression after NF- $\mathrm{KB}$ inhibition}

Although TNF $\alpha$ can elicit apoptosis in some tumor cells in vitro and in some experimental tumor models, limited responses are obtained with systemic delivery of TNF $\alpha$ because of toxicity and resistance of tumor cells to induced cell death ${ }^{15}$. TNF $\alpha$ has shown efficacy in combination with interferon- $\gamma$ against some sarcomas and melanomas, using limb perfusion approaches ${ }^{16}$. TNF $\alpha$ disrupts tumor vasculature endothelium ${ }^{17}$ through reduction of expression of $\alpha \mathrm{V} \beta 3$ integrin ${ }^{18}$, but does not have a direct killing effect on tumor cells. TNF $\alpha$ can elicit apoptosis in cell culture if NF-kB is inhibited ${ }^{8-11}$; thus, we sought to determine if similar results could be attained in tumors in vivo. We generated in nude mice fibrosarcoma tumors derived from $\mathrm{HT} 1080$ cells with an empty expression vector (HT1080V) or HT1080 cells expressing a modified form of the NF-kB inhibitor I $\mathrm{kB} \alpha$ (HT1080I cells; ref. 8). The modification of $I \kappa B \alpha$ blocks its ability to be phosphorylated and to be subsequently degraded, thereby preventing NF- $\mathrm{KB}$ translocation to the nucleus ${ }^{19}$. HT1080I cells are blocked in their ability to activate NF$\kappa B$ (ref. 8). Intratumoral injection of TNF $\alpha$ yields enhanced antitumor effects compared with systemic treatment ${ }^{15}$ and systemic delivery of high levels of TNF $\alpha$ is toxic in mice (data not shown). Thus, we assessed the anti-tumor effects after intratumoral administration of TNF $\alpha$ in HT1080V and HT1080I tumors of similar size. HT1080I tumors grow more slowly than HT1080V tumors. The HT1080I tumor mass was eradicated within 7 days, leaving only scar tissue after TNF $\alpha$ treatment (Fig. 1). Most HT1080I tumors (17 of 20) were eradicated by TNF $\alpha$, whereas only a few HT1080V tumors (3 of 20) regressed, presumably because of the effect of TNF $\alpha$ on tumor vasculature.

TNF $\alpha$ induces tumor apoptosis when NF- $\mathrm{KB}$ is inhibited TNF $\alpha$ causes 'hemorrhagic necrosis' of tumors through effects on tumor vasculature ${ }^{17,18}$; thus, we determined whether the effect of TNF $\alpha$ on HT1080l tumors was through apoptotic or necrotic mechanisms. We collected several HT1080V and HT1080I tumors after 16-24 hours of TNF $\alpha$ treatment and analyzed the samples by TUNEL assay (Fig. 2a-d), which detects DNA fragmentation and is commonly used to detect apoptosis. 
Fig. 1 TNF $\alpha$ induces tumor regression when NF-kB activation is blocked. HT1080V or HT1080I tumors were grown to similar size in nude mice. TNF $\alpha$ was injected intratumorally once a day for $3 \mathrm{~d}$ and mice were photographed $7 \mathrm{~d}$ after the final TNF $\alpha$ injection. Left, mouse with two HT1080I tumors (expressing the 'super-repressor' form of I $\mathrm{KB} \alpha$ ); right, mouse with two HT1080V tumors. Tumors responding with complete regression: I (HT1080I), 17 of 20 ; V (HT1080V), 3 of 20.

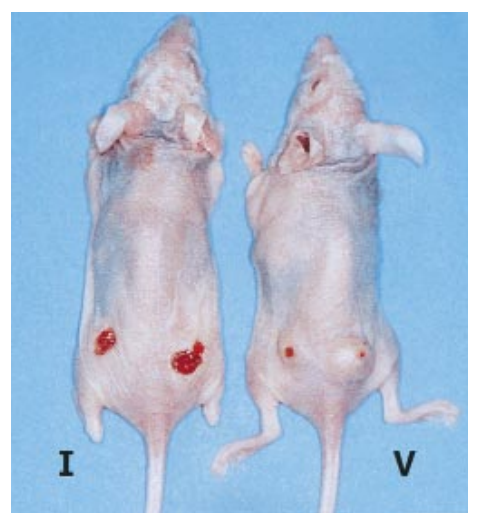

HT1080I tumors had widespread TUNEL-positive cells, in contrast to the staining of HT1080V tumors (Fig. 2d), indicating that TNF $\alpha$ elicited tumor cell apoptosis when NF-KB was inhibited. To confirm that TNF $\alpha$ caused tumor regression, we collected the tumor and surrounding soft tissue and examined their histology (Fig 2e-h). The HT1080I tumor treated with TNF regressed and was replaced by scar tissue consisting mainly of fibroblasts (Fig. 2h). There was some regression of the HT1080V tumor in response to TNF (Fig. 2g). Although the central portion of thetumor mass was destroyed, a peri pheral rim of apparently viable tumor tissue was spared (data not shown). Although we have no direct data on this, our result is consistent with reports showing that TNF $\alpha$ disrupts tumor microvasculature, leading to tumor necrosi $\mathrm{s}^{17,18}$.

\section{Potentiation of chemotherapy-induced cell death in vitro}

To explore gene therapy approaches relevant to the inhibition of $N F-\kappa B$, we used CDNA encoding the 'super-repressor' form of $\mathrm{I} \kappa \mathrm{B} \alpha$ (ref. 19) cloned into an adenovirus 5 vector to produce replication-defective Ad.CMV.I $\kappa B \alpha$ (ref. 20). To determine if the virus was effective in inhibiting NF-kB, we infected HT1080 cells with the control adenovirus Ad.CMV3 or with Ad.CMV.IкB $\alpha$ and treated these cells with TNF $\alpha$. Ad.CMV.I $\mathrm{kB} \alpha$, but not the control virus, blocked NF-KB induction and led to considerable cell death in the TNF $\alpha$-treated cells (data not shown). Next, we determined whether the I $\mathrm{kB} \alpha$-encoding virus would enhance

$\mathrm{V}=\mathrm{HT} 1080 \mathrm{~V}$

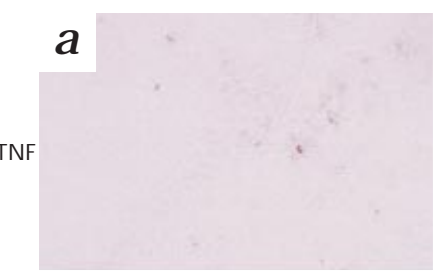

C

+TNF

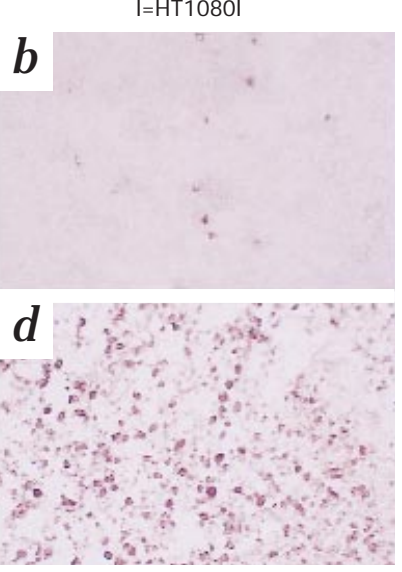

Fig. 2 Tumor regression induced by TNF $\alpha$ in NF- $\mathrm{KB}$ inhibited cells is due to apoptosis. HT1080V and HT1080I tumors were injected intratumorally with TNF $\alpha$ once a day for $3 \mathrm{~d}$. a-d, Measurement of apoptosis in HT1080V or HT1080I tumors after 16-24 h of TNF $\alpha$ treatment, shown by TUNEL staining. Apoptosis is widespread in the HT1080I tumor injected with TNF $\alpha$ apoptosis in HT1080 tumors in response to TNFa. Systemic delivery of TNF $\alpha$ in combination with the intratumoral injection of either control Ad.CMV3 or Ad.CMV.I $\mathrm{kB} \alpha$ produced lethal toxicity in the mice (data not shown). We therefore focused on enhancing chemotherapeutic responses in tumors.

The chemotherapeutic compound camptothecin (CPT), a topoisomerase I inhibitor, is effective against a variety of tumors ${ }^{21}$. Consistent with reports on topoisomerase inhibitors and other chemotherapies ${ }^{8,22-24}$, we found that camptothecin potently activated NF-KB in the HT1080 fibrosarcoma cells (Fig. 3a). NF- $\mathrm{KB}$ activation reached a maximum after 2 hours and was sustained in the nucleus after 7 hours. CPT-11, an analog of camptothecin, has broad anti-tumor function, and is one of the most promising anticancer drugs now in clinical trials ${ }^{25}$. The active metabolite of CPT-11, SN38, is responsible for anti-tumor activity in vivo ${ }^{26}$. Therefore, we determined whether SN38 activated NF-KB. SN 38 induced nuclear translocation of NF-KB in a dosedependent manner and at a concentration as low as $0.1 \mu \mathrm{M}$ (Fig. $3 b)$. The induced NF-KB was a classical heterodimer with a 50kDa subunit and a 65-kDa subunit, as confirmed by antibody 'supershift' analysis with p50 and p65 antibodies (Fig. 3c). Our p50 antibody is ineffective in 'supershifting' a p50-p65 heterodimer. To determine whether the activation of NF-KB had an effect on CPT- and SN38-induced cytotoxicity, we treated HT1080V or HT1080I cells with CPT or SN38 for 24 hours. The cytotoxicity generated by CPT or SN38 was en hanced considerably by inactivation of NF-kB, although less so at the lower concentrations of drug (Fig. 3d).

\section{Enhanced CPT-11-mediated apoptosis and tumor regression}

To determine if the inhibition of NF-kB would enhance antitumor responses of CPT-11, we established HT1080 tumors by subcutaneous injection of cells in nude mice. We injected tumors with either control virus (Ad.CMV3), the adenovirus encoding the 'super-repressor' form of I $\mathrm{kB} \alpha$ (Ad.CMV.I $\mathrm{kB} \alpha$ ) or vehicle alone. We then treated mice systemically with either CPT-11 or with PBS and measured tumor volume for 20 days. Neither CPT-11 alone nor Ad.CMV.I KB $\alpha$ al one resulted in inhibition of tumor growth (Fig. 4). There was enhanced fibrosarcoma growth in the presence of chemotherapy alone. However, combined systemic CPT-11 treatment and tumor injection with
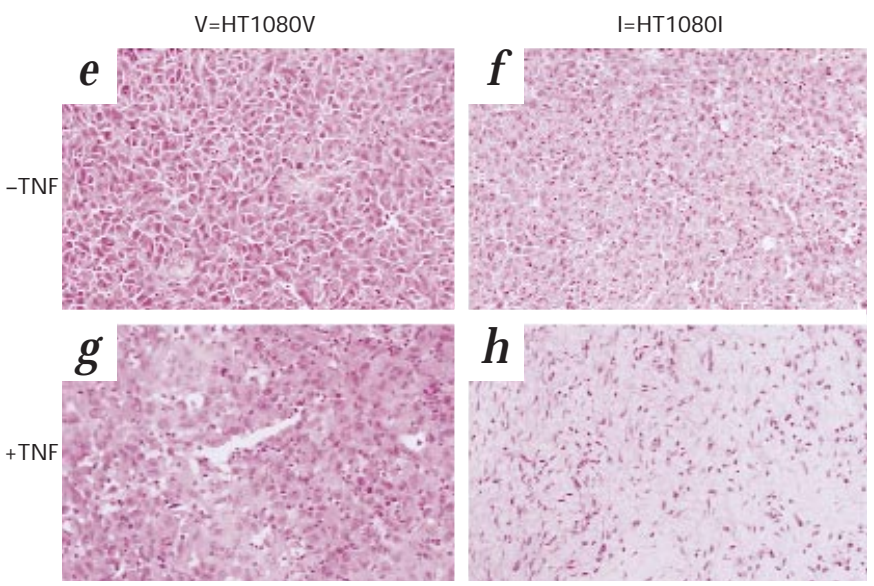

(d) but not in untreated HT1080I tumor (b) or in HT1080V treated (c) or untreated (a). e-h, Histology of the tumors. HT1080V and HT1080I tumors were collected 2 weeks after TNF $\alpha$ treatment. The HT1080I tumor treated with TNF $\alpha$ (h) regressed and was replaced by scar tissue, whereas the HT1080V tumor not treated with TNF $\alpha$ (g) continued to grow. 
v

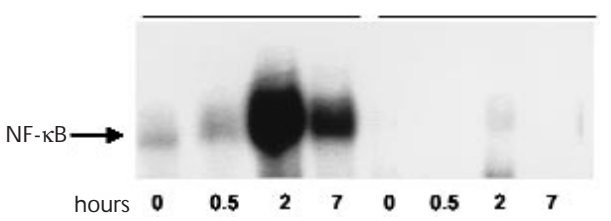

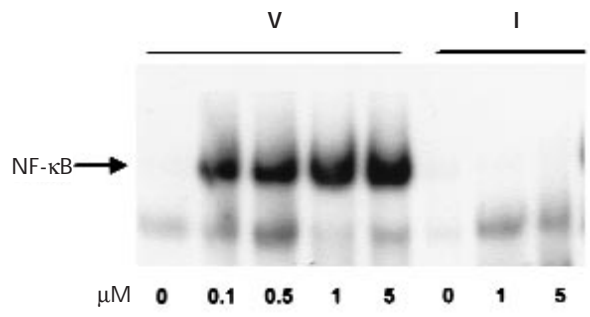

SN38

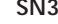

SN38

p65 p50 - p65 p50

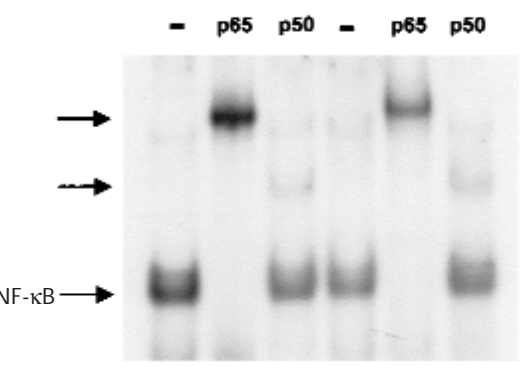

Fig. 3 Activation of NF- $\kappa B$ in human fibrosarcoma cells by CPT and SN38. a, Kinetics of activation of NF-KB by CPT. HT1080V and HT1080I cells were treated with $5 \mu \mathrm{M}$ CPT for $0.5,2$ and $7 \mathrm{~h}$. Nuclear extracts were analyzed by EMSA. Arrow, NF-kB mobility. $\mathbf{b}$, Activation of NF- $\mathrm{BB}$ in fibrosarcoma cells by SN38, the active metabolite of CPT11. HT1080V and HT1080I cells were treated with SN38 (concentrations in $\mu \mathrm{M}$ below blot) for $2 \mathrm{~h}$. c, Subunit composition of NF-kB activated by CPT or SN38. Nuclear extracts from CPT-treated or SN38 treated cells were pre-incubated with antibodies to the p50 and 65 subunits followed by EMSA. Arrows, mobilities of NF-kB and 'supershifted' complexes. d, Inhibition of NF-KB leads to enhanced cell death in response to CPT (left) or SN38 (right). HT1080V and HT1080I cells were treated with CPT or SN38 (concentrations in $\mu \mathrm{M}$ below graphs) for $24 \mathrm{~h}$; surviving cells were identified by crystal violet assay (vertical axis; as \% of surviving cells).
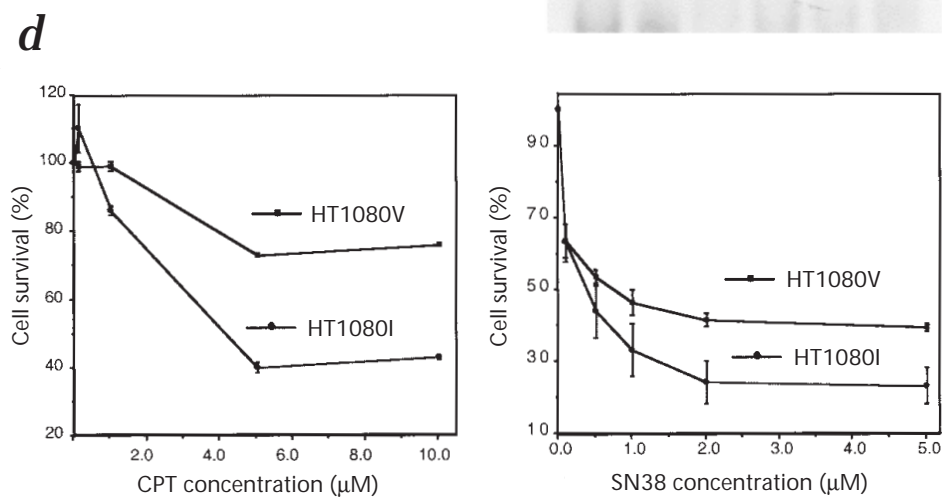

Ad.CMV.I $\kappa B \alpha$ (but not Ad.CMV3) elicited significant inhibition of tumor growth (Fig. 4). Furthermore, inhibition of tumor cell growth in vitro with combined chemotherapy and inhibition of NF-KB was attained with tumor cell lines expressing either wildtype or mutant p53, although the presence of wild-type p53 seemed to enhance the cell death response (J.C.C., R.L. and A.S.B., unpublished data).

To determine if the anti-tumor effect was elicited by apoptosis, we isolated tumors 48 hours after the initial viral treatment and 24 hours after the initial CPT-11 treatment and sectioned them for histology and TUNEL assays. CPT-11 treatment plus inhibition of NF-KB led to tumors with mostly apoptotic cells (Fig. 5). Treatment with CPT-11 alone or with Ad.CMV.IkB $\alpha$ alone yielded almost no apoptotic responses in the tumors. Moreover, NF-kB was activated in the tumors treated with CPT- 11 and th is activation was suppressed by expression of I $\mathrm{kB} \alpha$ (J.C.C, R.L. and A.S.B., unpublished data).

To determine if this enhanced anti-tumor response could be attained in other tumor models, we explored the use of Ad.CMV.I $\mathrm{kB} \alpha$ in combination with CPT-11 in the Lovo colorectal tumor model. CPT-11 and Ad.CMV.I $\mathrm{KB} \alpha$ in combination led to considerable suppression of tumor growth associated with a substantially enhanced apoptotic response, whereas CPT-11 or Ad.CM V.I $\mathrm{KB} \alpha$ alone were ineffective at inducing these responses (Table). These results show that CPT-11 was unable to elicit an apoptotic response in fibrosarcoma or colorectal tumors unless NF-kB was inhibited, establishing NF-kB as a principal mediator of inducible chemoresistance.

\section{Discussion}

Many cancer cells either show chemo- or radioresistance or acquire resistance after therapy ${ }^{27,28}$. Increased concentrations of cytotoxic drugs and higher dosages of irradiation fail to improve the pharmacotherapeutic response in resistant cancer cells. Thus, research efforts are aimed at determining the regulatory events involved in chemo- and radioresistance. Resistance to

apoptosis controls the ability of tumors to withstand high levels of chemotherapy and radiation ${ }^{1}$. Moreover, cells that are resistant to apoptosis seem to have a growth advantage in tumors ${ }^{29,30}$. Therefore, the development of approaches to lower the apoptotic threshold within tumor cells is likely to prove useful both as a direct cancer treatment and in combination with radiation and chemotherapy.

Resistance to cancer chemotherapy can be caused in many ways. One mechanism of chemoresistance is caused by overexpression of MDR1, a transmembrane protein that functions to export chemotherapeutic compounds from cells. Another mechanism seems to be inducible or acquired resistance of the tumor to apoptosis, which blocks the ability of chemotherapies and radiation to induce tumor cell death ${ }^{2}$. Acquired resistance

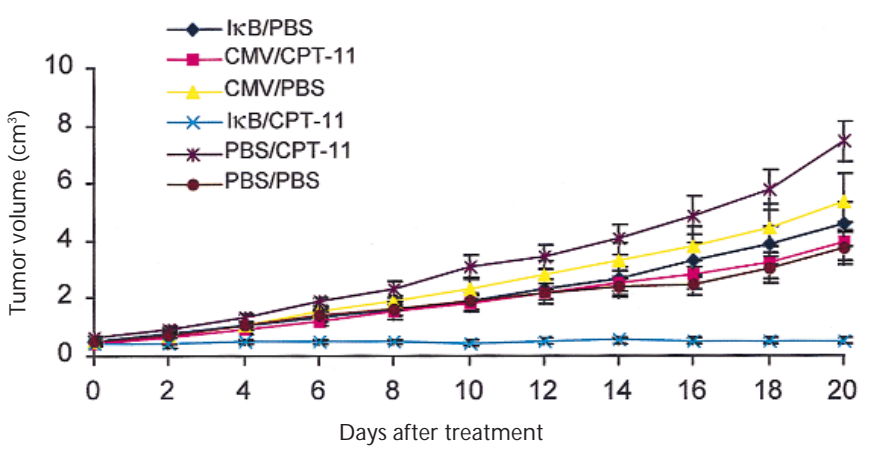

Fig. 4 Fibrosarcoma tumor growth inhibition in response to CPT-11 treatment and inhibition of NF-кB. HT1080 xenografts were injected intratumorally with Ad.CMV.IKB $\alpha$. Mice received CPT-11 intravenously $24 \mathrm{~h}$ later, then every $4 \mathrm{~d}$ (for five dosages). Virus was injected again 7 days after the first virus injection. Ad.CMV3 and vehicle alone, vector controls; PBS, drug treatment control. Tumor volume ( vertical axis) represents mean \pm s.e.m. ( $n=12-16$ per group) of one of two experiments. Tumor growth after combined treatment with the 'super-repressor' IкB $\alpha$ and CPT-11 was significantly less at day 20 than growth after treatment with either reagent alone $(P<0.001$, ANOVA). 

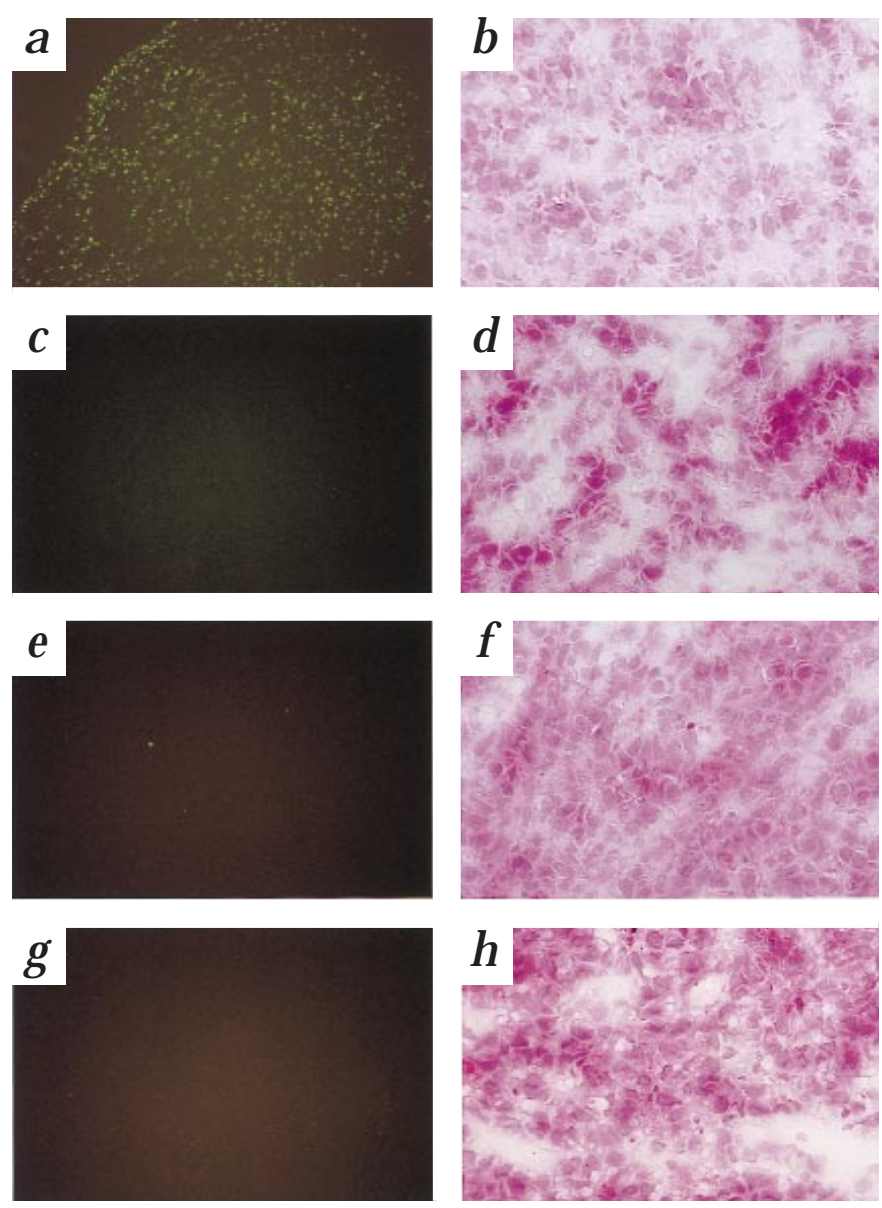

may result from mutations in p53 or overexpression of antiapoptotic proteins such as Bcl-2. Although there may be many mechanisms by which resistance to apoptosis is achieved in tumors, our data indicate that a main pathway involved in inducible resistance is the activation of the transcription factor $\mathrm{NF}-\kappa \mathrm{B}$ within tumor cells in response to chemotherapy or TNF $\alpha$. In either case, inhibition of cancer therapy-induced NF-кB activation strongly enhances the apoptotic potential of these stimuli. Our findings probably explain the lack of efficacy of TNF $\alpha$ in cancer trials $s^{15,16}$ and the reduced efficacy of chemotherapies in general ${ }^{1}$ and identify an important mechanism whereby tumors are induced to become resistant to cancer therapy. Consistent with our results, the use of combined approaches in cancer therapies has been described ${ }^{31-33}$, and it is much more efficacious than a single type of treatment.

How does NF-кB activation suppress apoptosis in tumor cells in response to TNF $\alpha$ or chemotherapy? Because the ability of TNF $\alpha$ to elicit an apoptotic response typically requires the inhibition of protein synthesis ${ }^{34}$, activation of NF- $\mathrm{kB}$ was assumed to induce transcription of genes that encode gene products that function to feed back and block apoptosis. Consistent with this, four gene products (TRAF1 and 2 and C-IAP1 and 2) are upregulated by $N F-\kappa B$ at the mRNA level that block the ability of TNF $\alpha$ to activate the apical caspase, caspase-8 (ref. 35). Like $T N F \alpha$, chemotherapy induces apoptosis through induction of the caspase cascade. c-IAP1 and 2 expression alone can suppress etoposide-induced apoptosis ${ }^{35}$, consistent with the ability of
Fig. 5 Induction of apoptosis by CPT-11 and inhibition of NF-кB in HT1080 fibrosarcoma tumors. HT1080 tumors were injected intratumorally with Ad.CMV.IkB $\alpha$ (a, $\mathbf{b}, \mathbf{g}$, and $\mathbf{h}$ ), Ad.CMV3 (control vector; $\mathbf{c}$ and $\mathbf{d}$ ) or PBS (vehicle; $\mathbf{e}$ and $\mathbf{f}$ ), then mice received an intravenous injection of CPT-11 (a-d) or PBS (vehicle; e-h) $24 \mathrm{~h}$ later. Tumors were collected $48 \mathrm{~h}$ after initial treatment (virus or PBS). Staining and original magnifications: a,c,e, and g, fluorescent TUNEL assay, $\times 10 ; b, d, f$ and $h$, hematoxylin and eosin, $\times 40$.

these proteins to block activation of the downstream caspases, caspase-3 and -7 (ref. 36). Apoptosis induced by chemotherapy seems to involve the upregulation of Fas ligand and induced cell killing controlled by Fas, at least in some cell types ${ }^{3}$. At present, it is not known whether the activation of NF- $\kappa B$ suppresses Fas-mediated cell killing and, if so, whether the same NF-кB-regulated gene products that suppress TNF $\alpha$-induced apoptosis can suppress Fas-induced apoptosis. Although p53 is involved in apoptosis induced by chemotherapy and radiation ${ }^{5}$, our preliminary data (unpublished) indicate that the enhanced apoptosis resulting from the combination of NF-kB inhibition and chemotherapy treatment is at least partially p53-independent. This is consistent with observations that oncogenic Ras induces apoptosis in a p53-independent manner when NF-kB is inhibited ${ }^{37}$.

Our results with TNF $\alpha$ and camptothecins provide a conceptual basis for improving the efficacy of chemotherapy and biologic-based anti-cancer therapy. The main target for TNF $\alpha$ in clinical cancer trials is the tumor microvasculature ${ }^{17,18}$. Our studies indicate that TNF $\alpha$ in parallel with NF- $\mathrm{kB}$ inhibition leads to direct tumor cell killing. At present, it is unclear whether this combined approach would augment or suppress the TNF $\alpha$ effect on disruption of microvasculature. Combined cancer treatment strategies that use inhibition of NF-kB may substantially augment the sensitivity of chemoresistant tumors and improve the clinical response rates in these tumors. For neoplasms that show chemosensitivity, the combined strategy may lower the level of chemotherapy needed to effectively elicit an anti-cancer re sponse. Given the results of studies with two tumor model systems and with a variety of tumor cell lines and chemotherapies, our results may be applicable to diverse tumors. However, we cannot rule out the possibility that certain tumors or certain chemotherapies may require NF- $\mathrm{KB}$ for inducing cell death.

The apoptotic response elicited in the tumors by CPT-11 and Ad.CMV.I $\mathrm{kB} \alpha$ injection is widespread. In fact, experimental conditions can be modified so that near-complete tumor regression is obtained by this approach (J.C.C. R.L. and A.S.B., unpublished data). LacZ staining after injection of HT1080 tumors with Ad.LacZ indicates that approximately $50 \%$ of tumor cells express

Table Tumoricidal response to combination CPT-11 and the super-repressor $\mathrm{I} \mathrm{KB} \alpha$ in Lovo xenografts

\begin{tabular}{|c|c|c|c|}
\hline Treatment group & $\begin{array}{l}\text { Tumor growth } \\
\text { response }^{a}\left(\mathrm{~cm}^{3}\right)\end{array}$ & $\begin{array}{l}\text { SR-IкB } \alpha \text { transgene } \\
\text { expression }^{\mathrm{b}}\end{array}$ & Apoptotic sc \\
\hline PBS/PBS & 3.92 & none & + \\
\hline Ad.CMV3/PBS & 2.09 & none & + \\
\hline PBS/CPT-11 & 2.88 & none & + \\
\hline Ad.CMV3/CPT-11 & 2.12 & none & + \\
\hline Ad.CMV.IкB $\alpha$ /CPT-11 & 0.43 & $+1+$ & $+1+$ \\
\hline Ad.CMV.IкB $\alpha / P B S$ & 2.58 & $+1+$ & + \\
\hline
\end{tabular}

Tumors were injected with virus or PBS, then mice were injected with CPT-11 or PBS $24 \mathrm{~h}$ later.,$+ 0-25 \%$ positive; + , $26-50 \%$ positive; $+H, 51-75 \%$ positive; and $+1+, 76-100 \%$ positive. The growth response ratio was calculated as the mean tumor volume on day 8 after treatment with CPT-11 or PBS (control). ${ }^{b}$ Super-repressor-I $\mathrm{k} \alpha \alpha$ transgene expression measured as the percentage of cells stained positive for the hemagluttinin-tagged epitope on the supre-repressor IкB $\alpha$ protein. 'Apoptotic score measured as the percentage of cells stained TUNEL-positive $24 \mathrm{~h}$ after treatment. 
detectable levels of $\beta$-galactosidase. Therefore, either the inhibition of NF-KB in a subset of cells leads to bystander tumor cell death, or the level of infection with the virus is near $100 \%$ and the use of LacZ as a marker for gene transduction underestimates the number of cells that actually express the modified form of I $\mathrm{KB} \alpha$. Consistent with the latter, I $\mathrm{\kappa B} \alpha$ expression can be detected in greater than $75 \%$ of cells in tumors injected with Ad.CMV.I $\mathrm{\kappa B} \alpha$. Whatever the mechanism, the data indicate that effective mechanisms to suppress NF- $\mathrm{KB}$ activation should be developed and used to lower the apoptotic threshold as an adjuvant approach for cancer chemotherapy. Successful efforts in the gene therapy of tumors ${ }^{33,38-41}$ and in the development of small molecule inhibitors of N F-kB (ref. 42) provide a logical basis for an adjuvant approach in cancer therapy to inhibit NF-KB and its associated anti-apoptotic function.

\section{Methods}

Cell cultures and adenovirus production. Stably transfected HT1080I cells were made as described ${ }^{8}$. HT1080V, HT1080I and Lovo cells were cultured in EMEM medium supplemented with $10 \%$ FCS, $100 \mu \mathrm{g} / \mathrm{ml}$ penicillin and streptomycin and $200 \mu \mathrm{g} / \mathrm{ml}$ hygromycin (for HT1080V and HT1080I). The control virus Ad.CMV3 was a gift from J. Roth (Houston, Texas) Recombinant adenovirus (either control or expressing the 'super-repressor' form of IкB $\alpha$; ref. 20) was prepared by the University of North Carolina Gene Therapy Center. The preparations of recombinant virus were shown to contain less than 1-5 wild-type adenovirus per $10^{6}$ virus.

Electrophoretic mobility shift assay (EMSA). Cell nuclear extracts (5-10 $\mu \mathrm{g})$ were preincubated with $1 \mu \mathrm{g}$ of poly (dl-dC) in binding buffer $(10 \mathrm{mM}$ Tris, $50 \mathrm{mM} \mathrm{NaCl}, 20 \%$ glycerol, $1 \mathrm{mM}$ DTT and $0.5 \mathrm{mM}$ EDTA) for $10 \mathrm{~min}$ at room temperature. Approximately $20,000 \mathrm{cpm}$ of ${ }^{32} \mathrm{P}$-labeled DNA probe containing the class I MHC NF-kB site was then added and allowed to bind for $15 \mathrm{~min}$. The complexes were separated by $5 \%$ polyacrylamide gel electrophoresis and detected by autoradiography.

Histology and deoxynucleotidyl transferase-mediated dUTP nick end labeling (TUNEL) assay. Animals were killed by asphyxiation in a $\mathrm{CO}_{2}$ chamber. The tumors or scar tissues were fixed in $4 \%$ paraformaldehyde at room temperature for $24 \mathrm{~h}$. The specimens were cut into sections $4 \mu \mathrm{m}$ in thickness and stained with hematoxylin and eosin. For TUNEL staining, the tumors were either untreated or treated intratumorally with TNF $\alpha$ for $16 \mathrm{~h}$. The tumors then were collected, embedded in OCT compound (Sakura, Tokyo, Japan) and 'snap frozen' in liquid nitrogen. Frozen sections $7 \mu \mathrm{m}$ in thickness were cut and fixed in $4 \%$ paraformaldehyde and stained according to the manufacturer's instructions (Boehringer). This assay measures DNA strand breaks and is therefore diagnostic for cells undergoing apoptosis.

Cell survival assay and adenovirus infection. HT1080V and HT1080I cells were left untreated or treated with CPT (Sigma) or SN38 (Pharmacia) for 24 h. The surviving cells were stained with $0.05 \%$ crystal violet in $20 \%$ ethanol. The dye was eluted and crystal violet staining was quantified at $595 \mathrm{~nm}$ wavelength using a kinetic microplate reader. The 'super-repressor' IkB $\alpha$ was cloned into the replication-deficient Ad5 vector with transgene expression driven by the CMV early promoter. The cells were pre-infected with Ad.CMV.IKB $\alpha$ or Ad.CMV3 empty control vector for $1 \mathrm{~h}$. After $24 \mathrm{~h}$ of infection, the cells were treated with $50 \mathrm{ng} / \mathrm{ml}$ TNF for $24 \mathrm{~h}$. The surviving cells were quantified by the crystal violet assay.

In vivo tumor growth and TNF treatment. HT1080I cells $\left(1 \times 10^{6}\right.$ cells $/ 0.1$ $\mathrm{ml}$ ) or control HT1080V cell suspensions were injected subcutaneously into each flank of female, athymic, nu/nu mice 5-6 weeks old (Taconic, Germantown, New York). Tumors were allowed to develop for $21 \mathrm{~d}$ and then were injected with TNF $\alpha(10 \mu \mathrm{g} / 100 \mu \mathrm{l}$ in PBS once a day for $3 \mathrm{~d})$. Both maximum and minimum diameters of resulting tumor were measured over the skin every 2 days using a slide caliper. At the end of experiments, the tumors were surgically removed under aseptic conditions and weighed. The tumors were then subjected to histological analysis and TUNEL assays.
Tumor studies with Ad.CMV.IאB $\alpha$ and CPT-11. Chemosensitization responses were evaluated in subcutaneous tumors grown in nu/nu mice. Tumor cells $\left(1 \times 10^{6}\right)$ were injected subcutaneously in the flanks of nu/nu, female, athymic nude mice 5-6 weeks old (body weight, 18-20 g). Tumors were treated 2-3 weeks after cancer cells were injected when tumor dimensions were approximately $1 \mathrm{~cm} \times 1 \mathrm{~cm}$. Tumor treatment involved the intratumoral injection of recombinant adenovirus Ad.CMV.IкB $\alpha$ (ref. 20), using a described technique ${ }^{43}$. Virus $\left(1 \times 10^{10} \mathrm{PFU}\right.$, diluted in a total of 200 $\mu$ l of PBS) was administered in a single pass of a 27-gauge hypodermic needle. A second virus injection was given $7 \mathrm{~d}$ after the first. The recombinant adenovirus Ad.CMV3 and vehicle alone were used as controls. CPT-11 (Irinotecan; Pharmacia \& Upjohn Company, Kalamazoo, Michigan) was administered by tail vein injection at a dose of $33 \mathrm{mg} / \mathrm{kg}$ in $100 \mu \mathrm{l}$ every $4 \mathrm{~d}$ beginning $24 \mathrm{~h}$ after the first viral injection. A total of five doses of CPT-11 were given. PBS $(100 \mu \mathrm{l})$ administered by tail vein injection was used as a control for drug treatment. Tumor diameter was measured along the longest orthogonal axes every other day after treatment was initiated, and recorded as tumor volume. Tumor volume was calculated by assuming a spherical shape, using the formula (volume $=4 / 3 \pi r^{3}$ ), where $r=1 / 2$ (mean tumor diameter measured in two dimensions).

Tumors were fixed in $10 \%$ formalin and embedded in paraffin blocks. Paraffin-embedded sections were pre-treated with dewax and rehydrated ( $55^{\circ} \mathrm{C}$ for $15 \mathrm{~min}$ ), then washed in xylene and rehydrated through a graded series of ethanol and redistilled water. Tissue sections were then incubated with proteinase $\mathrm{K}(20 \mu \mathrm{g} / \mu \mathrm{l}$ in $10 \mathrm{mM}$ Tris/ $\mathrm{HCl}, \mathrm{pH}$ 7.4-8.0, for $15 \mathrm{~min}$ at $21-37^{\circ} \mathrm{C}$ ), permeabilized in $0.1 \%$ Triton-X100 in $0.1 \%$ sodium citrate, and then labeled with the TUNEL reaction mixture (Boehringer).

\section{Acknowledgments}

The authors thank Y. Lin for assistance with statistical analysis. We also acknowledge J. Roth for Ad.CM V3. This work has been funded by the UNC Lineberger Comprehensive Cancer Center (J.C.C.), by the American Cancer Society Clinical Oncology Career Development Award 96-21 (J.C.C.) and by research grants CA73756, CA75080 and Al35098 (to A.S.B.) and CA75528 (to J.C.C.) from the NIH and by a Leukemia Society of America grant (to A.S.B.). Support for C.-Y.W. was provided by NIH grant DE12823. Additional support for this project was provided by the UNC SPORE program in breast cancer $(\mathrm{NCI}$ grant CA58223).

\section{RECEIVED 2 FEBRUARY; ACCEPTED 1 MARCH 1999}

1. Fisher, D.E. Apoptosis in cancer therapy: crossing the threshold. Cell 73, 539-542 (1994).

2. Baldini, N. Multidrug resistance-a multiplex phenomenon. Nature Med. 3, 378-380 (1997).

3. Friesen, C., Herr, I., Krammer, P. \& Debatin, K.-M. Involement of the CD95 (APO$1 /$ Fas) receptor/ligand system in drug-induced apoptosis in leukemia cells. Nature Med. 2, 574-577 (1996).

4. Fulda, S., Susin, S., Kroemer, G. \& Debatin, K.-M. Molecular ordering of apoptosis induced by anticancer drugs in neuroblastoma cells. Cancer Res. 58, 4453-4460 (1998).

5. Held, D.K. Radiation-induced apoptosis and its relationship to loss of clonogenic survival. Apoptosis 2, 265-282 (1997).

6. Tewari, M. \& Dixit, V. Recent advances in TNF and CD40 signaling. Curr. O pin. Gen. Dev. 6, 39-44 (1996).

7. Datta, R. et al. Activation of the CPP32 protease in apoptotis induced by 1- $\beta-D-a r a-$ binofuranosylcyotosine and other DNA damaging agents. Blood 88, 1936-1943 (1996).

8. Wang, C.-Y., Mayo, M.W. \& Baldwin, A.S. TNF- and cancer therapy-induced apoptosis: potentiation by inhibition of NF-KB. Science 274, 784-787 (1996).

9. Beg, A.A. \& Baltimore, D. An essential role for NF-KB in preventing TNF $\alpha$-induced cell death. Science 274, 782-784 (1996).

10. Van Antwerp, D., Martin, S.J., Kafri, T., Green, D.R. \& Verma, I. M. Suppression of TNF $\alpha$-induced apoptosis by NF- $\kappa B$. Science 274, 787-789 (1996).

11. Liu, Z.G., Hsu, H., Goeddel, D.V. \& Karin, M. Dissection of TNF receptor 1 effector functions: JNK activation is not linked to apoptosis while NF- $\mathrm{KB}$ activation prevents cell death. Cell 87, 565-576 (1996).

12. Arsura, M., Wu, M. \& Sonenshein, G.E. TGF $\beta 1$ inhibits NF- $\kappa B /$ Rel activity inducing

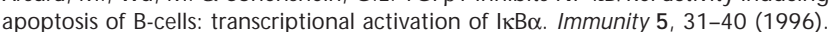

13. Baldwin, A.S. The NF- $\kappa B$ and IкB proteins: new discoveries and insights. Ann. Rev. Immunol. 14, 649-681 (1996).

14. Ghosh, S., May, M.J. \& Kopp, E.B. NF-кB and Rel proteins: evolutionarily conserved mediators of immune responses. Ann. Rev. Immunol. 16, 225-260 (1998).

15. Spriggs, D.R. \& Yates, D.R. in Tumor necrosis factors: The Molecules and their 
Emerging Roles in Medicine (ed. Beutler, B) 383-407 (Raven, New York, 1992).

16. Eggermont, A., Manusama, E. \& ten Hagen, T.L.M. Regional application of TNF $\alpha$ in the treatment of cancer: a preclinical-clinical interactive program. J. Inflamm. 47, 104-113 (1996).

17. Mauceri, H.J. et al. TNF $\alpha$ gene therapy targeted by ionizing radiation selectively damages tumor vasculature. Cancer Res. 56, 4311-4314 (1996).

18. Ruegg, C. et al. Evidence of the involvement of endothelial cell integrin $\alpha \mathrm{V} \beta 3$ in the disruption of the tumor vasculature induced by TNF and IFN $\gamma$. N ature M ed. 4, 408414 (1998).

19. Brockman, J.A. et al. Coupling of a signal response domain in $1 \kappa B \alpha$ to multiple pathways for NF-kB activation. M ol. Cell. Biol. 15, 2809-2818 (1995).

20. limuro, Y. et al. NF-кB prevents apoptosis and liver dysfunction during liver regeneration. J. Clin. Invest. 101, 802-811 (1998).

21. Takimoto, C.H. \& Arbuck, S.G. in Cancer Chemotherapy and Biotherapy (eds. B. Chabner, B. \& Longo, D.) 463-484 (Lippincott-Raven, New York, 1996).

22. Piret, B. \& Piette, J. Topoisomerase poisons activate the transcription factor NF-кB in ACH2 and CEM cells. Nucl. Acids Res. 24, 4242-4248 (1996).

23. Slater, A., Kimland, M., Jiang, S.A. \& Orrenius, S. Constitutive nuclear NF-кB/Rel DNA-binding activity of rat thymocytes is increased by stimuli that promote apoptosis, but not inhibited by pyrrolidine dithiocarbamate. Biochem. J. 312, 833-838 (1995).

24. Das, K.C. \& White, C.W. Activation of NF-kB by antineoplastic agents: role of protein kinase C. J. Biol. Chem. 272, 14914-14920 (1997).

25. Oshita, F. et al. Phase II study of irinotecan and etoposide in patients with metastatic non-small-cell lung cancer. J. Clin. Oncol. 15, 304-309 (1997).

26. Kawato, Y., Aonuma, M., Hirota, Y., Kuga, H. \& Sato, K. Intracellular role of SN-38, a metabolite of the camptothecin derivative CPT-11, in the antitumor effect of CPT11. Cancer Res. 51, 4187-4191 (1991).

27. Hickman, J.A. Apoptosis induced by anticancer drugs. Cancer Metastasis Rev. 11 121-139 (1992).

28. Kerr, J.F. et al. Apoptosis. Its significance in cancer and cancer therapy. Cancer $\mathbf{7 3}$ 2013-2026 (1994).

29. Merlino, G. Regulatory imbalances in cell proliferation and cell death during onco- genesis in transgenic mice. Sem. Cancer Biol. 5, 13-20 (1994).

30. Graeber, T.G. et al. Hypoxia-mediated selection of cells with diminished apoptotic potential in solid tumors. Nature 379, 88-91 (1996)

31. Chmura, S.J. et al. Decreasing the apoptotic threshold of tumor cells through protein kinase $C$ inhibition and spinghomyelinase activation increases tumor killing by ionizing radiation. Cancer Res. 57, 4340-4347 (1997).

32. Mauceri, H.J. et al. Combined effects of angiostatin and ionizing radiation in antitumor therapy. Nature 394, 287-291 (1998).

33. Heise, C. et al. ONYX-015, an E1B-gene attenuated adenovirus, causes tumor-specific cytolysis and antitumor efficacy that can be augmented by standard chemotherapeutic agents. Nature M ed. 3, 639-645 (1997).

34. Holtmann, H., Hahn, T. \& Wallach, D. Interrelated effects of TNF and IL-1 on cell viability. Immunobiology 177, 7-22 (1988).

35. Wang, C.-Y., Mayo, M.W., Korneluk, R.G., Goeddel, D.V. \& Baldwin, A.S. NF-kB antiapoptosis: induction of TRAF1, TRAF2, c-IAP1 and c-IAP2 to suppress caspase- 8 activation. Science 281, 1680-1683 (1998).

36. Roy, N., Devereaux, Q.L., Takahashi, R., Salvesen, G. \& Reed, J.C. EM BO J. 16, 6914 (1997).

37. Mayo, M. et al. Requirement of NF- $\mathrm{BB}$ activation to suppress p53-independent apoptosis induced by oncogenic Ras. Science 278, 1812-1815 (1997).

38. Arai, H., Gordon, D., Nabel, E.G. \& Nabel, G.J. Gene transfer of Fas ligand induces tumor regression in vivo. Proc. Nat. Acad. Sci. USA 94, 13862-13867 (1997).

39. Weichselbaum, R. and Kufe, D. Gene therapy of cancer. Lancet 349 (suppl.), 10sll-12sll (1997).

40. Roth, J.A. et al. Retrovirus-mediated wild-type p53 gene transfer to tumors of patients with lung cancer. Nature M ed. 2, 985-991 (1996).

41. Lowe, S. Progress of the smart bomb cancer virus. Nature M ed. 3, 606-608 (1997).

42. Conner, E.M. et al. Proteasome inhibition attenuates nitric oxide synthase expression, VCAM-1 transcription and the development of chronic colitis. J. Pharm. Exp. Ther. 282, 1615-1622 (1997).

43. Cusack, J.C. et al. High levels of gene transduction in human lung tumors following intralesional injection of recombinant adenovirus. Cancer Gene Ther. 3, 245-149 (1996). 